\title{
Prevalence and predictors of metabolically healthy obesity in adolescents: findings from the national "Jeeluna" study in Saudi- Arabia
}

Lara Nasreddine ${ }^{1 \dagger}$, Hani Tamim ${ }^{2 \dagger}$, Aurelie Mailhac $^{2}$ and Fadia S. AlBuhairan ${ }^{3,4^{*}}$

\begin{abstract}
Background: Obese children and adolescents may vary with respect to their health profile, an observation that has been highlighted by the characterization of metabolically healthy obesity (MHO). The objectives of this study were to examine the prevalence of $\mathrm{MHO}$ amongst obese adolescents in Saudi-Arabia, and investigate the anthropometric, socio-demographic, and lifestyle predictors of $\mathrm{MHO}$ in this age group.

Methods: A national cross-sectional school-based survey (Jeeluna) was conducted in Saudi-Arabia in 2011-2012 ( $n=1047$ obese adolescents). Anthropometric, blood pressure and biochemical measurements were obtained. A multicomponent questionnaire covering socio-demographic, lifestyle, dietary, psychosocial and physical activity characteristics was administered. Classification of $\mathrm{MHO}$ was based on two different definitions. According to the first definition, subjects were categorized as $\mathrm{MHO}$ based on the absence of the following traditional cardiometabolic risk (CR) factors: systolic blood pressure (SBP) or diastolic blood pressure (DBP) >90th percentile for age, sex, and height; triglycerides $(\mathrm{TG})>1.25 \mathrm{mmol} / \mathrm{L}$; high density lipoprotein-cholesterol $(\mathrm{HDL}-\mathrm{C}) \leq 1.02 \mathrm{mmol} / \mathrm{L}$; glucose $\geq 5.6 \mathrm{mmol} / \mathrm{L}$. The second definition of $\mathrm{MHO}$ was based on absence of any cardiometabolic risk factor, according to the International Diabetes Federation (IDF) criteria.

Results: The prevalence of MHO ranged between 20.9\% (IDF) and 23.8\% (CR). Subjects with MHO were younger, less obese, had smaller waist circumference (WC) and were more likely to be females. Based on stepwise logistic regression analyses, and according to the IDF definition, body mass index (BMI) $(\mathrm{OR}=0.89,95 \% \mathrm{Cl}: 0.84-0.93)$ and WC (OR $=0.97$, 95\% Cl: 0.96-0.98) were the only significant independent predictors of $\mathrm{MHO}$. Based on the CR definition, the independent predictors of $\mathrm{MHO}$ included female gender ( $\mathrm{OR}=1.76,95 \% \mathrm{Cl}$ : 1.29-2.41), BMI $(\mathrm{OR}=0.97,95 \% \mathrm{Cl}$ : 0.94-1.00), and weekly frequency of day napping (OR=1.06,95\% Cl: 1.00-1.12). Analysis by gender showed that vegetables' intake and sleep indicators were associated with $\mathrm{MHO}$ in boys but not in girls.

Conclusion: The study showed that one out of five obese adolescents is metabolically healthy. It also identified anthropometric factors as predictors of $\mathrm{MHO}$ and suggested gender-based differences in the association between diet, sleep and $\mathrm{MHO}$ in adolescents. Findings may be used in the development of intervention strategies aimed at improving metabolic heath in obese adolescents.
\end{abstract}

Keywords: Obesity, Adolescents, Metabolically healthy obesity, Prevalence, Predictors, Saudi Arabia, Middle-East

\footnotetext{
* Correspondence: falbuhairan@aldaramed.com

${ }^{\dagger}$ Lara Nasreddine and Hani Tamim contributed equally to this work.

${ }^{3}$ Department of Pediatrics and Adolescent Medicine, AlDara Hospital and

Medical Center, P.O. Box 1105, Riyadh 11431, Saudi Arabia

${ }^{4}$ Department of Population, Family, and Reproductive Health, Bloomberg

School of Public Health, Johns Hopkins University, Baltimore, MD, USA

Full list of author information is available at the end of the article
}

(c) The Author(s). 2018 Open Access This article is distributed under the terms of the Creative Commons Attribution 4.0 International License (http://creativecommons.org/licenses/by/4.0/), which permits unrestricted use, distribution, and reproduction in any medium, provided you give appropriate credit to the original author(s) and the source, provide a link to the Creative Commons license, and indicate if changes were made. The Creative Commons Public Domain Dedication waiver (http://creativecommons.org/publicdomain/zero/1.0/) applies to the data made available in this article, unless otherwise stated. 


\section{Background}

Pediatric obesity has become a global challenge in health care, plaguing both high and low-income nations and jeopardizing their ability to cope with the increasing cost of obesity management and treatment [1]. The Eastern Mediterranean Region (EMR), and particularly countries of the Gulf Cooperation Council (GCC), harbor one of the highest burdens of childhood obesity worldwide, with reported estimates exceeding $25 \%$ in some countries [2-4]. Childhood obesity is associated with numerous adverse health consequences, with both immediate and longerterm complications [5]. Among the immediate health risks are cardiometabolic abnormalities including insulin resistance, dyslipidemia, increased glucose levels, metabolic syndrome, and hypertension [5-7]. On the long term, childhood obesity tends to track into the adult years, increasing the risk for non-communicable diseases (NCDs), such as type 2 diabetes, cardiovascular diseases (CVDs), and certain types of cancer, while also being associated with mental health problems, such as low self-esteem and depression $[8,9]$.

Obesity is however being increasingly recognized as a "heterogeneous condition", a fact that has been emphasized by the identification and characterization of metabolically healthy obesity (MHO) amongst adults [10-12]. Despite being obese, these individuals do not present any of the traditional cardiometabolic risk factors that are usually associated with obesity $[10,11]$. It has been argued that this subgroup of obese subjects may have a lower mortality risk and a healthier medical prognosis, compared to their non-metabolically healthy obese counterparts [13-17]. Available studies have indicated that, amongst obese adults, the prevalence of MHO may range between 6 and 40\% [10, 11, 18, 19]. Similarly, it has been suggested that obese children may also vary in terms of their health profile [12, 20-22], but MHO in the pediatric population has not been well-characterized [12]. The investigation of $\mathrm{MHO}$ amongst children is important for several reasons. First, given the increasing need for weight management care, it may be necessary to prioritize specialized service delivery for those individuals with the greatest cardiometabolic risk [12]. By characterizing obese individuals according to their relative health risks, those at lower cardiometabolic risk may be directed towards less intensive management services (e.g. outpatient dietitian counseling, behavioral modification etc.), while their peers at higher risk may require more intensive health services (e.g., multidisciplinary obesity treatment or drug-based management) [12]. The recognition of childhood obesity as a heterogeneous condition implies that "a menu of therapeutic options" for children (and their caregivers) would be available to address their individual health needs, an approach that is in harmony with treating obesity as a chronic disease
$[12,23]$. Second, given the possible protective effects of $\mathrm{MHO}$ on disease risk, when compared to metabolically unhealthy obese (MUO), it would be crucial to investigate and identify the characteristics that are associated with the MHO status in youth and to foster our understanding of the factors that could prevent obese subjects from developing metabolic abnormalities [24-26].

In the Kingdom of Saudi-Arabia (KSA), like in several other countries of the EMR, the rate of obesity amongst children and adolescents is following an escalating secular trend [27]. A recent national study (Jeeluna) conducted in KSA showed that $15.9 \%$ of adolescents were obese [28], a proportion that is considerably higher than what was reported in the early 1990 s, where the prevalence of obesity was estimated at $6 \%$ in boys and $6.7 \%$ in girls aged $1-18$ years [29]. This alarming trend coupled with the probable protective effect of $\mathrm{MHO}$ on morbidity, highlights the need to investigate and better characterize $\mathrm{MHO}$ in the pediatric years. This study builds on the "Jeeluna" national study to examine the proportions of obese adolescents who are metabolically healthy in KSA and to investigate socio-demographic, anthropometric, and lifestyle predictors of $\mathrm{MHO}$ in this age group. Due to the lack of a universal definition for $\mathrm{MHO}$, two commonly used definitions will be adopted in this study to assess the prevalence and factors associated with MHO in this population $[12,30]$. The selected definitions are based on traditional cardiometabolic risk factors that are easily measured and are routinely obtained in clinical practice.

\section{Methods}

Study design

This study is based on the national cross-sectional school-based survey (Jeeluna) that was conducted in KSA in 2011-2012 [28]. Details on the design, sampling protocol and data collection are published elsewhere [28]. In brief, a nationally representative sample $(n=12,575)$ of students attending intermediate/ secondary schools in KSA participated in the "Jeeluna" study [28]. A stratified, cluster random sampling procedure was adopted with sampling occurring in all of the 13 administrative regions in the country. Within each region, several school districts exist, with a total of 42 districts in the country. Sampling occurred at the district level, ensuring that both rural, as well as urban/suburban areas were covered. Based on the student population per region, district, gender, and school level (intermediate vs. secondary), proportionate sampling was performed. For the selection of the schools, any male/female, intermediate/secondary, public/private school in a city/town in the KSA that operates during the day was eligible. Evening schools and schools that only cater for students with special needs 
were excluded from this study. Using a computer-based randomized sampling, schools were drawn from the list of intermediate and secondary schools enlisted with the Ministry of Education. Within the selected schools, classes were randomly chosen. Sampling was clustered whereby all students within a selected class were invited to participate in the study. An information letter describing the study objectives and protocol was sent to students and their parents.

The study protocol was approved by the institutional review board (IRB) and ethics committee at King Abdullah International Medical Research Center (KAIMRC) and the Ministry of Education (MOE). Prior to accessing the selected schools, permission was obtained from the schools' principals. Written parental consent and student assent were obtained prior to subjects' enrollment in the study [28]. Students were given the choice of opting out of blood sampling. Students were assured that all the responses that they provided on the questionnaire would remain anonymous and confidential.

\section{Study participants}

For the present study, the selection of subjects from the original survey participants $(n=12,575)$ was undertaken according to the following criteria: 1) having provided blood samples; 2) not exceeding 19 years of age; and 3) being obese.

Of the total sample of 12,575 subjects, 7329 had consented to blood withdrawal and provided blood samples (response rate: 58.3\%). Of those, 51 were above 19 years old and were thus excluded, yielding a sample of 7278 subjects. According to the World Health Organization (WHO) new growth standards [31], obesity was defined based on sex and age, as +2 body mass index (BMI) $z$-scores [31]; the WHO AnthroPlus software (WHO, Geneva, Switzerland) was utilized to calculate BMI $z$-scores. To allow for comparisons with previous studies conducted in KSA, prevalence rates of obesity were also determined using the Centers for Disease Control and Prevention (CDC) 2000 criteria [32]. Accordingly, of the 7278 subjects who have provided blood samples and who were aged less than 19 years, 1179 (16.20\%) were obese based on the WHO criteria and 1176 (16.16\%) were obese based on the CDC criteria. For the remaining analyses, the WHO criteria were retained. In addition, subjects with missing information on blood pressure measurements, waist circumference or biochemical assessment (lipid profile; fasting glucose), were excluded $(n=132)$. Consequently, the final sample for this study included 1047 subjects.

\section{Data collection}

Data collection included: (1) completion of self-administered multi-component questionnaire; (2) anthropometric and blood pressure measurements; and (3) blood sampling and biochemical assessment. Data collection was conducted by trained personnel who received standardized and structured training prior to the initiation of the study. Other quality control measures were implemented, including the pre-testing of the questionnaire, equipment, and data collection protocols as well as the field monitoring of data collection.

\section{Completion of the multi-component questionnaire}

The study questionnaire was developed based on the Youth Risk Behavior Survey [33] and the Global School-based Student Health Survey [28, 34]. Since Arabic is the native language in KSA, the Arabic version of the GSHS questionnaire was used [35]. In addition, questions adopted from the YRBS were translated to Arabic and reviewed for translational appropriateness. Cultural adaptation was introduced to the questionnaire. For instance, questions that were considered culturally inappropriate such as sexual behaviors and sexually transmitted diseases, were not included. In addition, questions related to the subject's family, lifestyle, sleep, and health status were added. The questionnaire was reviewed for content validity by an expert panel, which included an adolescent medicine physician, a pediatrician, an epidemiologist, a public health professional, and a school health professional [36]. It is worth noting that previous investigations that were based on the same tools (Arabic version of GSHS and Arabic translation of YRBS) have reported a high internal consistency, with a Cronbach Alpha of 0.84 [37].

The questionnaire was pilot-tested on a sample of adolescents and questions or statements that were found difficult, unclear, or ambiguous to the participating adolescents were further refined or modified [36]. For instance, examples were added to clarify some questions, such as examples of main meals, snacks, vegetables, or energy drinks. In addition, the option to choose more than one response if needed was added to some questions. None of the items included in the questionnaire were found to be inappropriate or distressing to the pilot sample of adolescents and thus, none of the questions were completely eliminated [36]. The final amended version of the questionnaire was adopted for data collection (http://kaimrc.med.sa/?page_id=5036).

As such, the final version of the questionnaire covered several domains, including socio-demographic, dietary practices, sleep habits, sedentarity, physical activity, behaviors that contribute to unintentional injuries and violence, tobacco use, alcohol and substance use, history of bullying, mood, health status, and access to health services. The questionnaire was self-administered. 


\section{Anthropometric measurements}

Anthropometric measurements were taken using standardized protocols [38] and calibrated equipment. Height was measured to the nearest $0.5 \mathrm{~cm}(\mathrm{~cm})$ and body weight to the nearest $0.1 \mathrm{~kg}(\mathrm{~kg})$ using an electronic scale (Omron SC100 digital scale; Omron Healthcare, Inc., Lake Forest, IL), in light indoor clothing and with bare feet or stockings [28]. BMI was calculated as the ratio of weight (kilograms) to the square of height (meters). Waist circumference was measured at the midpoint between the costal margin and iliac crest at the end of expiration using a non-elastic flexible tape measure and was recorded to the nearest millimeter $(\mathrm{mm})$ [39]. Measurements were taken twice and the average was adopted.

\section{Blood pressure measurements}

Blood pressure (BP) was measured in the supine position by a digital BP monitor (Omron M2, Netherlands) on the right arm. After a period of rest, measurements were taken twice a few minutes apart and recorded as an average using appropriate cuff size.

\section{Biochemical assessment}

Licensed phlebotomists/nurses collected blood samples from the students who consented to blood withdrawal, after an 8- h fast. Blood samples were collected in serum separator tubes (BD, USA), labeled, transported at cool temperature to the hospital lab upon collection, allowed to clot for more than $15 \mathrm{~min}$ and then centrifuged for $10 \mathrm{~min}$ at $3000 \mathrm{rpm}$ using a Multifuge 35R centrifuge at room temperature. The serum samples were either immediately assayed by an Architect 8000c clinical chemistry analyzer (Abbott, USA) or stored in the freezer at $70{ }^{\circ} \mathrm{C}$ for further testing. The specimens were not stored for longer than three months due to the instability of lipids in vitro. Lipid tests were performed. In addition, glucose level was also measured on the same analyzer using the hexokinase method. Three levels of quality control were performed for each assay (Bio-Rad, USA). The patient results were stored in the Laboratory Information System (LIS) (Cerner, USA), which was interfaced with the Architect 8000c clinical chemistry analyzer. The data were then retrieved from the LIS and integrated within the Jeeluna database.

\section{Definition of metabolically healthy obesity (MHO)}

We applied two different definitions to examine the prevalence and factors associated with MHO. The first definition was the one proposed by Prince et al. [12], according to which subjects were categorized as MUO or MHO, based on the presence or absence of the following four traditional cardiometabolic risk (CR) factors (MHO: 0 risk factor; MUO: > 1 risk factors): systolic blood pressure (SBP) or diastolic blood pressure (DBP) >90th percentile for age, sex, and height [40]; triglycerides (TG) > $1.25 \mathrm{mmol} / \mathrm{L}[41,42]$; high density lipoprotein-cholesterol $(\mathrm{HDL}-\mathrm{C}) \leq 1.02 \mathrm{mmol} / \mathrm{L}$; and glucose $\geq 5.6 \mathrm{mmol} / \mathrm{L}[12]$.

The second definition of $\mathrm{MHO}$ was based on the International Diabetes Federation (IDF) criteria. Accordingly, participants were dichotomized as $\mathrm{MHO}$ or MUO based on the presence or absence of the following risk factors: amongst those aged between 10 and 16 years old: SBP $\geq 130$ or $\mathrm{DBP} \geq 85 \mathrm{mmHg}$; $\mathrm{TG} \geq 1.7 \mathrm{mmol} / \mathrm{L} ; \mathrm{HDL}-\mathrm{C}<$ $1.03 \mathrm{mmol} / \mathrm{L}$; glucose $\geq 5.6 \mathrm{mmol} / \mathrm{L}$ and waist circumference (WC) $\geq 90$ th percentile for age and sex or adult cut-off if lower [30, 43]. Amongst those aged between 16 and 19 years old: $\mathrm{SBP} \mathrm{BP} \geq 130$ or diastolic $\mathrm{BP} \geq 85 \mathrm{mmHg}$; $\mathrm{TG} \geq 1.7 \mathrm{mmol} / \mathrm{L}$; HDL-C $<1.03 \mathrm{mmol} / \mathrm{L}$ in males and $<$ $1.29 \mathrm{mmol} / \mathrm{L}$ in females; glucose $\geq 5.6 \mathrm{mmol} / \mathrm{L}$ and $\mathrm{WC} \geq$ $94 \mathrm{~cm}$ for males and $\geq 80 \mathrm{~cm}$ for girls.

\section{Data analysis}

Identical analyses were conducted for both the IDF and CR definitions. Subjects' characteristics were described with number and percent for categorical variables and mean and standard deviation for continuous ones. The chi-square test and the independent t-test were used to assess statistically significant differences between groups (MHO vs MUO). We set statistical significance at a two-sided $p$-value of $<0.05$. The associations between MHO status and subjects' characteristics (socio-demographic, anthropometric, dietary, physical activity, sleep, smoking and psychosocial characteristics) were further assessed by creating a logistic regression model with $\mathrm{MHO}$ as a dependent variable, and with adjustment for age and sex. Stepwise logistic regression analyses (forward selection) was conducted to determine the independent predictors of MHO. The potential predictors that were entered into the final multivariate regression models included those that were significantly associated with $\mathrm{MHO}$, based on either the IDF or CR definitions, in the age and sex adjusted regression analyses. Moreover, given that available evidence suggests a sleep-gender interaction [25, 44], we tested for a potential interaction between gender and sleep related variables in our study sample. An interaction term was created for gender and number of hours of sleep during weekdays, for gender and number of hours of sleep during week-ends, and for gender and frequency of daytime napping. The interaction terms were entered separately into the logistic regression models, and the interaction was assessed for both models (Model-IDF definition and Model-CR definition). Whenever significant interaction was found, results were reported for both genders separately. Results were reported as odds ratio (OR), and 95\% confidence interval (95\% CI). We performed all data management and analyses using the Statistical Analysis Software (Version 9.1; 2004). 


\section{Results}

Of the study sample, $62.6 \%$ were boys and $37.4 \%$ were girls. The age of the study participants ranged between 10 and 19 years, with a mean of 15.9 years $( \pm 1.9)$ in boys and 15.6 years $( \pm 1.8)$ in girls. The large majority of the students participating in the study were of Saudi nationality (84.9\%) (data not shown).

As shown in Tables 1, 219 subjects out of 1047 (20.9\%, 95\% confidence interval (CI): 18.4-23.4) were categorized as MHO based on the IDF definition and 249 out of 1047 (23.8\%, 95\% CI: 21.2-26.4) were categorized as MHO based on the CR definition. The results showed that $12.8 \%$ of the participants were classified as being MHO based on both definitions (IDF and CR), while $68.1 \%$ were categorized as MUO by both categorizations (data not shown).

Gender disparities were noted in the proportions of MHO and MUO, according to both definitions (Table 1). Significant differences in age were observed with the IDF definition only, whereby subjects with MHO were younger. Across both the IDF and CR categories, the MHO group was significantly shorter, lighter, and less obese (lower BMI values and lower BMI $\mathrm{z}$ scores) than their MUO peers (Table 1$)$. WC $(\mathrm{cm})$ was significantly

Table 1 Socio-demographic, anthropometric and cardiometabolic status amongst adolescents $(n=1047)$ in KSA by MUO or $\mathrm{MHO}$ status

\begin{tabular}{|c|c|c|c|c|c|c|}
\hline & IDF & & & $\mathrm{CR}$ & & \\
\hline & $\begin{array}{l}\text { MUO } \\
(n=828)\end{array}$ & $\begin{array}{l}\text { MHO } \\
(n=219)\end{array}$ & $p$-value & $\begin{array}{l}\mathrm{MUO} \\
(n=798)\end{array}$ & $\begin{array}{l}\mathrm{MHO} \\
(n=249)\end{array}$ & p-value \\
\hline \multicolumn{7}{|l|}{ Socio-demographic } \\
\hline Age (years) & $15.88 \pm 1.85$ & $15.41 \pm 1.86$ & 0.0008 & $15.77 \pm 1.85$ & $15.81 \pm 1.91$ & 0.81 \\
\hline \multicolumn{7}{|l|}{ Gender } \\
\hline Males & $534(64.5)$ & $121(55.3)$ & 0.01 & $520(65.2)$ & $135(54.2)$ & 0.002 \\
\hline Females & $294(35.5)$ & $98(44.8)$ & & $278(34.8)$ & $114(45.8)$ & \\
\hline \multicolumn{7}{|l|}{ Father's level of education } \\
\hline Elementary or less & $145(19.7)$ & $35(18)$ & 0.84 & $128(18.1)$ & $52(23.2)$ & 0.17 \\
\hline Intermediate-high school & $331(45)$ & $91(46.7)$ & & $330(46.7)$ & $92(41.1)$ & \\
\hline University or higher & $259(35.2)$ & $69(35.4)$ & & $248(35.1)$ & $80(35.7)$ & \\
\hline \multicolumn{7}{|l|}{ Mother's level of education } \\
\hline Elementary or less & $251(33.7)$ & $57(28.9)$ & 0.45 & $235(32.8)$ & $73(32.2)$ & 0.82 \\
\hline Intermediate- high school & $291(39)$ & $81(41.1)$ & & 285 (39.8) & $87(38.3)$ & \\
\hline University or higher & $204(27.4)$ & $59(30)$ & & $196(27.4)$ & $67(29.5)$ & \\
\hline \multicolumn{7}{|l|}{ Anthropometric } \\
\hline Height (cm) & $162.78 \pm 10.43$ & $158.08 \pm 11.42$ & $<0.0001$ & $162.2 \pm 10.97$ & $160.5 \pm 10.2$ & 0.03 \\
\hline Weight (kg) & $88.45 \pm 17.4$ & $77.11 \pm 14.27$ & $<0.0001$ & $86.94 \pm 17.63$ & $83.31 \pm 16.4$ & 0.004 \\
\hline BMI $\left(\mathrm{kg} / \mathrm{m}^{2}\right)$ & $33.28 \pm 5.43$ & $30.76 \pm 4.25$ & $<0.0001$ & $32.93 \pm 5.44$ & $32.19 \pm 4.79$ & 0.04 \\
\hline BMI Z score & $2.82 \pm 0.75$ & $2.5 \pm 0.57$ & $<0.0001$ & $2.78 \pm 0.74$ & $2.67 \pm 0.66$ & 0.02 \\
\hline WC (cm) & $93.32 \pm 18.78$ & $80.97 \pm 16.84$ & $<0.0001$ & $91.08 \pm 19.55$ & $89.65 \pm 17.37$ & 0.27 \\
\hline Elevated WC & $447(54.0)$ & $0(0.0)$ & $<0.0001$ & $357(44.7)$ & $90(36.1)$ & 0.02 \\
\hline \multicolumn{7}{|l|}{ Cardiometabolic } \\
\hline $\mathrm{SBP}(\mathrm{mm} \mathrm{Hg})$ & $127.66 \pm 11.96$ & $118.05 \pm 7.8$ & $<0.0001$ & $128.6 \pm 11.32$ & $116.19 \pm 8.08$ & $<0.0001$ \\
\hline $\mathrm{DBP}(\mathrm{mm} \mathrm{Hg})$ & $72.84 \pm 10.85$ & $67.75 \pm 8.7$ & $<0.0001$ & $73.37 \pm 10.88$ & $66.64 \pm 7.9$ & $<0.0001$ \\
\hline $\mathrm{TC}(\mathrm{mmol} / \mathrm{L})$ & $4.35 \pm 0.78$ & $4.24 \pm 0.62$ & 0.04 & $4.36 \pm 0.77$ & $4.2 \pm 0.66$ & 0.001 \\
\hline $\mathrm{HDL}-\mathrm{C}(\mathrm{mmol} / \mathrm{L})$ & $1.13 \pm 0.23$ & $1.29 \pm 0.2$ & $<0.0001$ & $1.13 \pm 0.24$ & $1.27 \pm 0.19$ & $<0.0001$ \\
\hline LDL-C (mmol/L) & $2.79 \pm 0.7$ & $2.63 \pm 0.6$ & 0.001 & $2.8 \pm 0.69$ & $2.63 \pm 0.64$ & 0.0007 \\
\hline TG $(\mathrm{mmol} / \mathrm{L})$ & $1.26 \pm 0.76$ & $0.87 \pm 0.29$ & $<0.0001$ & $1.3 \pm 0.76$ & $0.79 \pm 0.21$ & $<0.0001$ \\
\hline Glucose (mmol/L) & $4.62 \pm 0.96$ & $4.41 \pm 0.67$ & 0.0003 & $4.63 \pm 0.97$ & $4.4 \pm 0.67$ & $<0.0001$ \\
\hline
\end{tabular}

Numbers are presented as Mean \pm SD or as proportions, $\mathrm{n}(\%)$

Abbreviations: BMI: Body mass index; cm: Centimeters; CR: Cardiovascular risks; DBP: Diastolic blood pressure; HDL-C: High density lipoprotein-cholesterol; IDF: International Diabetes Federation; kg: Kilograms; kg/m²: Kilograms per squared meters; KSA: Kingdom of Saudi Arabia; LDL-C: Low density lipoprotein-cholesterol; MHO: Metabolically healthy obesity; mm Hg: Millimeters of mercury; mmol/L:Millimoles per liter; MUO: Metabolically unhealthy obesity; SBP: Systolic blood pressure; SD: Standard deviation; TC: Total cholesterol; TG: Triglycerides; WC: Waist circumference 
lower amongst MHO subjects based on the IDF definition. Similarly, the proportion of subjects with elevated WC was significantly lower amongst MHO subjects, based on the CR categorization. As expected, cardiometabolic risk factors were in the less healthy direction in the MUO group.

Table 2 shows the dietary and lifestyle characteristics of the study population. In approximately $60 \%$ of the study subjects, the daily frequency of fruits' consumption was nil, while another equal proportion reported no consumption of milk. Similarly, $60 \%$ of the study subjects reported an intake of two or more soft drinks per day. Around half of the adolescents reported irregular breakfast consumption, no intake of vegetables, no exercise at school, and inadequate sleep on week days as well as week-ends. More than $80 \%$ of the study population reported screen time exceeding $2 \mathrm{~h}$ per day. There were no significant differences between the MHO and MUO groups in dietary and lifestyle characteristics, except for the weekly frequency of day napping, which was found to be significantly higher in the MHO group based on the $\mathrm{CR}$ definition. Psychosocial variables were also investigated amongst the study subjects (Additional file 1: Table S1). There were no significant differences in any of the psychosocial variables between $\mathrm{MHO}$ and MUO groups, according to both definitions.

The predictors of MHO status, after adjustment for age and sex, are shown in Table 3. Across both definitions, female gender was associated with higher odds of MHO $(\mathrm{OR}=1.43,95 \% \mathrm{CI}: 1.06-1.94$ based on IDF; $\mathrm{OR}=1.59$, 95\% CI: $1.19-2.12$ based on CR). Age was significantly inversely associated with $\mathrm{MHO}$, based on the IDF categorization $(\mathrm{OR}=0.88$; 95\% CI: 0.81-0.95). Compared to the lowest level of fathers' education (elementary or less), an intermediate or high-school educational level was associated with lower odds of MHO based on the CR definition, and the association was close to significance (OR $=0.68,95 \%$ CI: 0.46-1.02). Across both definitions, there was a significant inverse association between $\mathrm{MHO}$, weight, BMI and BMI-z score, with the latter being the strongest anthropometric predictor of MHO. There was also a negative association between $\mathrm{WC}(\mathrm{cm})$ and $\mathrm{MHO}$ based on the IDF definition, while elevated WC was associated with lower odds of $\mathrm{MHO}$ based on the $\mathrm{CR}$ categorization. The daily frequencies of vegetable and soft drink consumption were associated with lower odds of MHO, based on the CR and IDF definitions, respectively. Meeting the sleep recommendations during weekdays as well as the weekly frequency of day napping, were positively associated with $\mathrm{MHO}$. Across both definitions, there was no association between MHO and any of the psychosocial variables under investigation (data not shown).

Stepwise logistic regression was carried out to determine the independent predictors of MHO (Table 4). The model included the variables that were significantly associated with MHO (for either definition) after age and sex adjustment. As such, the final model included age, gender, BMI $\left(\mathrm{kg} / \mathrm{m}^{2}\right)$, WC $(\mathrm{cm})$, father's level of education, frequency of vegetable consumption per day, frequency of soft drinks' consumption per day, sleep hours per night, and daytime napping. It is important to note that, since the final model included both age and sex, we selected BMI $\left(\mathrm{kg} / \mathrm{m}^{2}\right)$ instead of BMI-z score, given that the latter already adjusts for inter-individual differences in age and sex. In addition, since significant interactions were found between gender, the number of sleep hours during week-days, and the frequency of napping, analyses were performed for boys and girls separately as well as for the total study population. Based on the IDF definition, BMI and WC were the only significant independent predictors of $\mathrm{MHO}$ in the overall sample. Based on the CR categorization, the significant independent predictors of $\mathrm{MHO}$ included female gender, BMI and the weekly frequency of day napping. Gender-disparities in $\mathrm{MHO}$ predictors were noted. MHO defined as per the IDF criteria was associated with BMI and WC in both genders, but in boys, the predictors also included the weekly frequency of consuming 2 vegetables per day (in comparison with a reference intake of $0 /$ day). The weekly frequency of day napping as well as meeting the sleep recommendations during week-days also reached borderline significance in boys, but not in girls. Based on the $C R$ categorization, the significant independent predictors of MHO included BMI and the frequency of soft drink consumption in girls, and father's level of education in boys.

\section{Discussion}

This study is the first to investigate $\mathrm{MHO}$ amongst adolescents in the Eastern Mediterranean Region. The study showed that approximately one in five obese adolescents in KSA was identified as metabolically healthy, despite being obese. In agreement with previous reports $[12,21$, 45-53], subjects with $\mathrm{MHO}$ were significantly younger, less obese, had smaller waist circumference and were more likely to be females. In addition, sleep habits and vegetable intake were found to be significantly associated with $\mathrm{MHO}$ in the study population, particularly in boys. Interestingly, the factors that predicted $\mathrm{MHO}$ varied depending on the definition that was used to identify subjects as MHO or MUO.

The study findings showed that the prevalence of $\mathrm{MHO}$ amongst obese adolescents in KSA (20.9-23.8\%) falls within the range reported in the literature (3.9-49.3\%) [12, 22, 45-56]. Caution must however be exerted when comparing prevalence estimates of $\mathrm{MHO}$ given that various studies may have adopted different definitions and that some studies included both overweight and obese 
Table 2 Dietary and lifestyle characteristics amongst adolescents $(n=1047)$ in KSA by MUO or MHO status

\begin{tabular}{|c|c|c|c|c|}
\hline IDF & 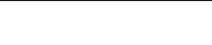 & & $C R$ & \\
\hline $\begin{array}{l}\text { MUO } \\
(n=828)\end{array}$ & $\begin{array}{l}\mathrm{MHO} \\
(n=219)\end{array}$ & $p$-value & $\begin{array}{l}\text { MUO } \\
(n=798)\end{array}$ & $\begin{array}{l}\mathrm{MHO} \\
(n=249)\end{array}$ \\
\hline
\end{tabular}

Dietary habits

Regular breakfast consumption during the past month

No

Yes

Frequency of snacks consumption/d

0

1

$\geq 2$

Frequency of fruits consumption/d

0

1

$\geq 2$

Frequency of vegetables consumption/d

0

1

$\geq 2$

Frequency of soft drinks consumption/d

$$
\begin{aligned}
& \leq 1 \\
& \geq 2
\end{aligned}
$$

Frequency of energy drinks consumption/d

$$
0
$$$$
\geq 1
$$

Frequency of milk consumption/d

0

1

$\geq 2$

Frequency of fast food consumption/week

Physical Activity and sedentarity

Exercise in school

$$
\text { No }
$$$$
\text { Yes }
$$

Frequency of exercise for at least $30 \mathrm{mn}$ during the past week

Screen time

$$
\leq 2 \mathrm{~h} / \mathrm{d}
$$$$
>2 \mathrm{~h} / \mathrm{d}
$$

Sleep

Number of hours of sleep per night, during week days

$$
\begin{aligned}
& \text { Adequate } \\
& \text { Inadequate }
\end{aligned}
$$

0.11

$116(53.7)$

0.27

$112(51.9)$

$124(57.4)$

$48(22.2)$

$44(20.4)$

$503(61.1)$

$134(61.5)$

$27(12.4)$

$57(26.2)$

385 (46.8)

266 (32.3)

100 (46.1)

$65(30)$

$52(24)$

$95(44.2)$

$120(55.8)$

0.15

$170(78.3)$

0.63

$47(21.7)$

0.39

0.51

0.59

468 (57.3)

129 (60.3)

0.73

$54(25.2)$

$2.03 \pm 1.94$

$1.87 \pm 1.78$

0.29

486 (59.7)

130 (60.8)

0.78

$328(40.3)$

84 (39.3)

0.51

132 (18.7)

37 (19.5)

0.81

481 (59.7)
$437(55.3)$
$207(26.2)$
$147(18.6)$

131 (53.3)

0.5

54 (22)

475 (59.9)

119 (15)

162 (65.3)

0.31

199 (25.1)

33 (13.3)

53 (21.4)

357 (45)

263 (33.2)

$128(51.8)$

0.14

173 (21.8)

68 (27.5)

51 (20.7)

317 (39.9)

$477(60.1)$

$98(40.0)$

147 (60.0)

629 (79.2)

198 (80.5)

0.67

165 (20.8)

48 (19.5)

449 (57.1)

148 (60.4)

0.66

215 (27.4)

$62(25.3)$

122 (15.5)

35 (14.3)

$2.03 \pm 1.95$

$1.9 \pm 1.76$

0.36

464 (59)

$152(62.8)$

0.29

322 (41)

$90(37.2)$

$1.8 \pm 2.36$

$1.52 \pm 2.2$

0.11

126 (18.5)

43 (20)

0.63

554 (81.5)

$172(80)$

467 (60)

113 (46.5)

0.07

Number of hours of sleep per night, during weekends 
Table 2 Dietary and lifestyle characteristics amongst adolescents $(n=1047)$ in KSA by MUO or MHO status (Continued)

\begin{tabular}{|c|c|c|c|c|c|c|}
\hline & IDF & & & $C R$ & & \\
\hline Adequate & $334(48.1)$ & $92(50.8)$ & 0.52 & $323(48.4)$ & $103(49.5)$ & 0.78 \\
\hline Inadequate & $360(51.9)$ & $89(49.2)$ & & $344(51.6)$ & $105(50.5)$ & \\
\hline $\begin{array}{l}\text { Number of days went to sleep during the } \\
\text { day in the past week }\end{array}$ & $3.79 \pm 2.86$ & $3.86 \pm 2.95$ & 0.73 & $3.69 \pm 2.89$ & $4.14 \pm 2.83$ & 0.03 \\
\hline \multicolumn{7}{|l|}{ Smoking } \\
\hline \multicolumn{7}{|l|}{ Smoking cigarettes during the past month } \\
\hline No & $746(91.2)$ & $196(91.2)$ & 0.99 & $715(91)$ & $227(91.9)$ & 0.65 \\
\hline Yes & $72(8.8)$ & $19(8.8)$ & & $71(9)$ & $20(8.1)$ & \\
\hline \multicolumn{7}{|l|}{ Smoking Shisha during the past month } \\
\hline No & $755(92.4)$ & $200(93.5)$ & 0.6 & $726(92.6)$ & $229(92.7)$ & 0.95 \\
\hline Yes & $62(7.6)$ & $14(6.5)$ & & $58(7.4)$ & $18(7.3)$ & \\
\hline
\end{tabular}

Screen time was assessed based on the time spent watching television, using the internet, chatting and playing videogames

Adequate sleep defined as a minimum of $9 \mathrm{~h}$ for 10-12 year old adolescents and as a minimum of $8 \mathrm{~h}$ for those aged13 years or older [82]

Abbreviations: CR: Cardiovascular risks; d: Day; IDF: International Diabetes Federation; KSA: Kingdom of Saudi Arabia; MHO: Metabolically healthy obesity; mn:

Minutes; MUO: Metabolically unhealthy obesity

subjects when assessing MHO. In certain studies, the definition of MHO was based on the presence of insulin resistance as estimated by Homeostasis Model Assessment (HOMA) [12, 21, 22, 48, 50], or as the presence of less than 2 cardiometabolic risk factors [21, 45-47, 54], while in others, including the present study, MHO was identified based on the absence of any cardiometabolic risk factor $[12,22,48,49,51-53,55,56]$. In addition, the criteria adopted to define individual cardiometabolic abnormalities were often discrepant between studies, and included those proposed by the IDF, the National Cholesterol Education Program (NCEP), the modified Adult treatment Panel III (ATPIII), as well as other ethnic specific criteria. Based on the CR definition proposed by Prince et al. (2014) [12], the prevalence of MHO obtained in this study (23.8\%) was lower than the one reported amongst 817 year old overweight and obese Canadian children (MHO: 31.5\%) and amongst obese German children (mean age: $11.6 \pm 2.8$ years) (MHO: 49.3\%) [51]. The younger age of the children participating in these studies and the fact that both overweight and obese children were included in the study by Prince et al. (2014) [12] may explain the higher proportion of MHO in these studies, compared to our results. Based on the IDF definition, the prevalence of MHO obtained in this study (20.9\%) was similar to the one reported amongst obese children and adolescents (10-18 years old) in Belgium (18.6\%) [22], and lower than the estimate reported amongst obese youth aged 8-18 years in Austria (30.7\%) [55]. Importantly, the results of this study highlighted poor agreement between definitions in classifying subjects as $\mathrm{MHO}$, whereby only $12.8 \%$ of the participants were classified as MHO based on both the IDF and CR definitions. Poor agreement between various MHO definitions has also been described by other studies [12, 48], underscoring the need for a harmonized definition for the identification of $\mathrm{MHO}$ in clinical as well as research settings.

It remains important to note that, at the time of this study, the MHO subjects were healthier than their MUO peers based on measures of traditional cardiometabolic health risk, but it is unknown whether this discrepancy would remain stable over time or whether it may be extrapolated to other health domains (such as musculoskeletal, respiratory) or whether the inclusion of other indicators of cardiovascular health (e.g., apo B, inflammatory markers, insulin resistance) would impact the MHO prevalence estimates obtained in this study [12]. It has been debated that MHO may not be a stable phenotype and there are unanswered questions on whether it represents a transient phenotype, changing with age, from childhood into adulthood [57]. However, based on the Bogalusa Heart Study, where 1098 individuals had participated both as children (5-17 years) and as adults (24-43 years), Li et al. (2012) showed that MHO children had favorable cardiometabolic profiles and carotid intima media thickness (CIMT) in adulthood compared with MUO children, thus providing evidence that the MHO phenotype starts in childhood and continues into adulthood [58] .

In this study, and in concordance with other reports, there were differences in how MHO related to adiposity, socio-demographic and lifestyle predictors, depending on the classification used to define MHO. First, WC was significantly associated with $\mathrm{MHO}$, based on both the IDF and CR definitions, independently of age and sex, thus highlighting the importance of measuring WC in clinical settings. However, in the fully adjusted model, WC remained an independent predictor of MHO based on the IDF definition only, and not the CR definition. Similar results were obtained by other studies that have 
Table 3 Association of socio-demographic, anthropometric, dietary and lifestyle characteristics with MHO after age and sex adjustment

\begin{tabular}{|c|c|c|c|c|}
\hline & IDF-MHO & & CR-MHO & \\
\hline & OR $(95 \% \mathrm{Cl})^{*}$ & $p$-value & OR $(95 \% \mathrm{Cl})^{*}$ & $p$-value \\
\hline \multicolumn{5}{|l|}{ Socio-demographic } \\
\hline Age (years) & $0.88(0.81-0.95)$ & 0.001 & $1.02(0.94-1.10)$ & 0.65 \\
\hline \multicolumn{5}{|l|}{ Gender } \\
\hline Males & reference & & reference & \\
\hline Females & $1.43(1.06-1.94)$ & 0.02 & $1.59(1.19-2.12)$ & 0.002 \\
\hline \multicolumn{5}{|l|}{ Father's level of education } \\
\hline Elementary or less & reference & & reference & \\
\hline Intermediate or high school & $1.13(0.73-1.76)$ & 0.58 & $0.68(0.46-1.02)$ & 0.06 \\
\hline University or higher & $1.07(0.68-1.70)$ & 0.76 & $0.83(0.55-1.25)$ & 0.37 \\
\hline \multicolumn{5}{|l|}{ Mother's level of education } \\
\hline Elementary or less & reference & & reference & \\
\hline Intermediate or high school & $1.18(0.80-1.73)$ & 0.4 & $0.99(0.69-1.42)$ & 0.95 \\
\hline University or higher & $1.23(0.82-1.87)$ & 0.32 & $1.14(0.77-1.68)$ & 0.5 \\
\hline \multicolumn{5}{|l|}{ Anthropometric } \\
\hline Weight (Kg) & $0.95(0.94-0.96)$ & $<0.0001$ & $0.99(0.98-1.00)$ & 0.01 \\
\hline BMI $\left(\mathrm{Kg} / \mathrm{m}^{2}\right)$ & $0.87(0.83-0.91)$ & $<0.0001$ & $0.96(0.93-1.00)$ & 0.03 \\
\hline BMI Z score & $0.36(0.26-0.51)$ & $<0.0001$ & $0.78(0.62-0.98)$ & 0.03 \\
\hline$W C(\mathrm{~cm})$ & $0.97(0.96-0.98)$ & $<0.0001$ & $1.00(0.99-1.01)$ & 0.74 \\
\hline Elevated WC & NA & & $0.74(0.55-1.00)$ & 0.05 \\
\hline \multicolumn{5}{|l|}{ Dietary Habits } \\
\hline \multicolumn{5}{|c|}{ Regular breakfast consumption in the past month } \\
\hline No & reference & & reference & \\
\hline Yes & $0.90(0.66-1.23)$ & 0.51 & $1.09(0.81-1.47)$ & 0.55 \\
\hline \multicolumn{5}{|c|}{ Frequency of snacks consumption/d } \\
\hline$\geq 3$ & reference & & reference & \\
\hline 2 & $0.77(0.49-1.22)$ & 0.27 & $0.79(0.52-1.21)$ & 0.28 \\
\hline$\leq 1$ & $1.01(0.68-1.50)$ & 0.96 & $0.81(0.56-1.17)$ & 0.27 \\
\hline \multicolumn{5}{|l|}{ Frequency of fruits consumption/d } \\
\hline 0 & reference & & reference & \\
\hline 1 & $0.78(0.49-1.25)$ & 0.3 & $0.83(0.54-1.27)$ & 0.38 \\
\hline$\geq 2$ & $1.04(0.73-1.49)$ & 0.81 & $0.81(0.57-1.15)$ & 0.24 \\
\hline \multicolumn{5}{|c|}{ Frequency of vegetables consumption/d } \\
\hline 0 & reference & & reference & \\
\hline 1 & $0.89(0.63-1.27)$ & 0.54 & $0.70(0.50-0.98)$ & 0.04 \\
\hline$\geq 2$ & $1.12(0.76-1.65)$ & 0.56 & $0.83(0.57-1.20)$ & 0.32 \\
\hline \multicolumn{5}{|c|}{ Frequency of soft drinks consumption/d } \\
\hline$\geq 2$ & reference & & reference & \\
\hline$\leq 1$ & $0.73(0.54-1.00)$ & 0.05 & $0.94(0.70-1.26)$ & 0.66 \\
\hline \multicolumn{5}{|c|}{ Frequency of power drinks consumption/d } \\
\hline$\geq 1$ & reference & & reference & \\
\hline 0 & $0.86(0.60-1.25)$ & 0.43 & $1.04(0.72-1.49)$ & 0.84 \\
\hline
\end{tabular}


Table 3 Association of socio-demographic, anthropometric, dietary and lifestyle characteristics with MHO after age and sex adjustment (Continued)

\begin{tabular}{|c|c|c|c|c|}
\hline & IDF-MHO & & CR-MHO & \\
\hline 0 & reference & & reference & \\
\hline 1 & $0.85(0.59-1.21)$ & 0.36 & $0.88(0.63-1.24)$ & 0.48 \\
\hline$\geq 2$ & $0.87(0.56-1.35)$ & 0.53 & $0.91(0.60-1.39)$ & 0.67 \\
\hline Frequency of fast food consumption/week & $0.97(0.90-1.06)$ & 0.50 & $0.98(0.91-1.06)$ & 0.58 \\
\hline \multicolumn{5}{|l|}{ Physical Activity and Sedentarity } \\
\hline \multicolumn{5}{|l|}{ Exercise in school } \\
\hline No & reference & & reference & \\
\hline Yes & $1.19(0.81-1.74)$ & 0.37 & $1.13(0.79-1.61)$ & 0.51 \\
\hline \multicolumn{5}{|l|}{ Screen Time } \\
\hline$>2$ h/day & reference & & reference & \\
\hline$\leq 2 \mathrm{~h} /$ day & $1.01(0.67-1.52)$ & 0.96 & $1.08(0.73-1.59)$ & 0.71 \\
\hline Frequency of exercise for at least $30 \mathrm{mn}$ in the past week & $0.98(0.91-1.04)$ & 0.45 & $0.96(0.90-1.02)$ & 0.21 \\
\hline \multicolumn{5}{|l|}{ Sleep } \\
\hline \multicolumn{5}{|l|}{ Number of sleep hrs per night, during week days } \\
\hline Inadequate & reference & & reference & \\
\hline Adequate & $1.31(0.97-1.78)$ & 0.08 & $1.34(1.00-1.80)$ & 0.05 \\
\hline \multicolumn{5}{|l|}{ Number of sleep hrs per night, during weekends } \\
\hline Inadequate & reference & & reference & \\
\hline Adequate & $1.10(0.79-1.53)$ & 0.57 & $1.03(0.75-1.41)$ & 0.86 \\
\hline Number of days went to sleep during the day in the past week & $1.02(0.97-1.08)$ & 0.44 & $1.05(1.00-1.11)$ & 0.05 \\
\hline \multicolumn{5}{|l|}{ Smoking } \\
\hline \multicolumn{5}{|l|}{ Smoking cigarette during the past month } \\
\hline Yes & reference & & reference & \\
\hline No & $0.75(0.43-1.30)$ & 0.3 & $1.00(0.59-1.71)$ & 0.99 \\
\hline \multicolumn{5}{|l|}{ Smoking shisha during the past month } \\
\hline Yes & reference & & reference & \\
\hline No & $0.88(0.47-1.63)$ & 0.68 & $0.88(0.50-1.55)$ & 0.66 \\
\hline
\end{tabular}

*Analyses were adjusted for age and sex except for BMI Z score since this variable already adjusts for inter-individual differences in age and sex Abbreviations: BMl: Body mass index; Cl: Confidence interval; cm: Centimeters; CR: Cardiovascular risks; d: Day; hrs: Hours; IDF: International Diabetes Federation; kg: Kilograms; kg/m²: Kilograms per squared meters; MHO: Metabolically healthy obesity; mn: Minutes; OR: Odds ratio; WC: Waist circumference

adopted the CR definition. For instance, Prince et al. (2014) has shown that WC was no longer significantly related with $\mathrm{MHO}$ in Canadian children, after adjustment for lifestyle factors [12]. In addition, the results of this study showed that, based on both definitions, BMI$\mathrm{z}$ score was the strongest predictor of $\mathrm{MHO}$ amongst adolescents in KSA, and that, after adjustment for dietary and lifestyle factors, BMI was more strongly associated with $\mathrm{MHO}$, compared to WC. These results are in agreement with those reported by a longitudinal study amongst adolescents, where BMI and its changes over time were more strongly related to cardiovascular factors compared with WC [51]. It is important to acknowledge that WC may not always be reflective of visceral fat as it is not able to differentiate between subcutaneous fat in the abdominal area and visceral fat accumulation [59].
Taken together, these findings suggest that the screening of an obese adolescent may include $\mathrm{WC}$ as a proxy of abdominal obesity $[60,61]$, in conjunction with BMI which may be able to better predict metabolic health in this age group. It has in fact been argued that BMI is one of the most consistent determinants of $\mathrm{MHO}$ in adolescents $[12,52,56]$ and that MHO status may not be really found at higher levels of obesity [21].

In this study, we found an association between the frequency of consumption of vegetables and $\mathrm{MHO}$ amongst boys, but not girls. Gender-based differences in the association of diet composition with $\mathrm{MHO}$ have been previously reported amongst adults [44] but no studies have examined these differences in children and adolescents. Such gender-based disparities may reflect differences in physiology or in the reporting of dietary 
Table 4 Independent associations of socio-demographic, anthropometric, and lifestyle characteristics with MHO status

\begin{tabular}{|c|c|c|}
\hline Model-IDF definition* & OR $(95 \% \mathrm{Cl})$ & $p$-value \\
\hline \multicolumn{3}{|l|}{ Among All } \\
\hline $\mathrm{BMI}\left(\mathrm{kg} / \mathrm{m}^{2}\right)$ & $0.89(0.84-0.93)$ & $<0.0001$ \\
\hline WC $(\mathrm{cm})$ & $0.97(0.96-0.98)$ & $<0.0001$ \\
\hline \multicolumn{3}{|l|}{ Model-CR definition* } \\
\hline Female Gender & $1.76(1.29-2.41)$ & 0.0004 \\
\hline $\mathrm{BMI}\left(\mathrm{kg} / \mathrm{m}^{2}\right)$ & $0.97(0.94-1.00)$ & 0.06 \\
\hline Number of days went to sleep during the day in the past week & $1.06(1.00-1.12)$ & 0.04 \\
\hline \multicolumn{3}{|l|}{ Among Boys } \\
\hline \multicolumn{3}{|l|}{ Model-IDF definition* } \\
\hline $\mathrm{BMI}\left(\mathrm{kg} / \mathrm{m}^{2}\right)$ & $0.91(0.85-0.96)$ & 0.001 \\
\hline WC (cm) & $0.97(0.96-0.99)$ & $<0.0001$ \\
\hline Frequency of vegetable consumption/d, $\geq 2 /$ day & $1.77(1.07-2.91)$ & 0.02 \\
\hline Number of sleep hours during week days, adequate & $1.51(0.99-2.35)$ & 0.07 \\
\hline Number of days went to sleep during the day in the past week & $1.07(0.99-1.16)$ & 0.08 \\
\hline \multicolumn{3}{|l|}{ Model-CR definition* } \\
\hline Father's level of education, intermediate-high school & $0.60(0.39-0.92)$ & 0.02 \\
\hline \multicolumn{3}{|l|}{ Among Girls } \\
\hline \multicolumn{3}{|l|}{ Model-IDF definition* } \\
\hline $\mathrm{BMI}\left(\mathrm{kg} / \mathrm{m}^{2}\right)$ & $0.84(0.77-0.92)$ & 0.0001 \\
\hline WC $(\mathrm{cm})$ & $0.97(0.96-0.99)$ & 0.0005 \\
\hline \multicolumn{3}{|l|}{ Model-CR definition* } \\
\hline $\mathrm{BMI}\left(\mathrm{kg} / \mathrm{m}^{2}\right)$ & $0.95(0.89-1.00)$ & 0.06 \\
\hline Frequency of soft drinks consumption/d, $\leq 1 /$ day & $0.49(0.30-0.81)$ & 0.006 \\
\hline \multicolumn{3}{|c|}{$\begin{array}{l}\text { *For each definition of MHO, the variables included in the model were: age (by unit increase of } 1 \text { year), gender (reference: male), BMI (by unit increase of } 1 \mathrm{~kg} / \\
\mathrm{m}^{2} \text { ), waist circumference (by unit increase of } 1 \mathrm{~cm} \text { ), father's level of education (reference: lowest), frequency of vegetables' consumption per day (reference: } 0 \text { ), } \\
\text { Frequency of soft drinks' consumption per day (reference: } \geq 2 \text { ), Number of sleep hours per night, during week days (reference: }<9 \mathrm{~h} \text { for } 6-12 \text { years old; }<8 \mathrm{~h} \text { for } \\
\text { those aged } 13 \text { years and above), number of days went to sleep during the day (by unit increase of } 1 \text { day). Since the model included age and gender as variables, } \\
\text { we included BMI in the regression model instead of BMI-zcore, given that the latter already adjusts for inter-individual differences in age and sex } \\
\text { Abbreviations: BMI: Body mass index; Cl: Confidence interval; cm: Centimeters; CR: Cardiovascular risks; hrs: Hours; IDF: International Diabetes Federation; kg } / \mathrm{m}^{2} \text { : } \\
\text { Kilograms per squared meters; MHO: Metabolically healthy obesity; OR: Odds ratio; WC: Waist circumference }\end{array}$} \\
\hline
\end{tabular}

intakes between sexes. The combination of phytochemicals, antioxidants, and dietary fiber brought by a diet rich in vegetables may decrease oxidative stress, mitigate the inflammatory response, improve insulin sensitivity and decrease cardio-metabolic risk, which may explain our study findings [62]. It is worth noting that some studies have reported a positive association of $\mathrm{MHO}$ with the intake of milk and fruits, and an inverse association with the consumption of soft drinks [47, 50, 54], while other studies found no association between $\mathrm{MHO}$ and food groups' intakes [12, 48]. Surprisingly, our results showed that, in girls, a lower intake of soft drinks was associated with lower odds of MHO. This may be due to the fact that adolescent girls, and particularly those with high adiposity, tend to under-report their intakes of energy-dense, nutrient-poor foods [63-65]. It is important to note that the questionnaire adopted in this study was qualitative in nature, and did not obtain quantitative information on portions or serving sizes usually consumed. In addition, the questionnaire did not allow for the estimation of energy and macronutrient intakes, and hence differences between $\mathrm{MHO}$ and MUO groups in this respect, could not be investigated.

Based on the CR definition, the results showed that meeting the recommended number of sleep hours per night was associated with higher odds of $\mathrm{MHO}$ in the total sample, after adjustment for age and sex. This sleep indicator was also associated with $\mathrm{MHO}$ in boys, based on the IDF definition. These findings are in line with those reported by Li et al. (2015) amongst Chinese children and adolescents, where MHO subjects had significantly longer sleep hours, and with those reported by Spruyt et al. (2010), where shorter sleep durations among children in the United States (US) were strongly associated with adverse metabolic outcomes such as higher plasma levels of insulin, low density lipoprotein (LDL) and high sensitivity C-reactive protein [50, 66]. Interestingly, the results of our study have also shown 
that the weekly frequency of day napping was an independent positive predictor of MHO status, particularly in boys. Studies on the association between day napping and metabolic health are scarce. In adults, longer napping durations (>60-90 $\mathrm{mn}$ ) were associated with higher risk of Metabolic syndrome and incidence of coronary heart disease, while this association was not observed for shorter nap durations $(<30-60 \mathrm{mn})$ [67-69]. In high school students, afternoon or evening naps, as assessed by actigraphy, were associated with higher levels of interleukin 6, while this association was not found for morning naps [70]. The same study has reported that diary-reported napping was not associated with any inflammatory marker. In addition, although some studies have suggested that daytime naps may be associated with reduced nocturnal sleep and with increased food craving amongst adolescents [71], others have found no association between daytime sleep and increased risk of adiposity in children and adolescents [72, 73]. It has been proposed that nighttime sleep and naps serve different physiological functions. Naps may in fact reduce daytime psychosocial stress and cortisol levels, which may, at least partly explain the observed associations in our study $[72,74,75]$.

It is of interest that, in our study, sleep indicators were associated with $\mathrm{MHO}$ in boys only, and not in girls. Gender-based differences in the association between sleep and metabolic health have been previously described amongst adults [25], but few studies have tackled this association in adolescents. In a nationally representative survey of 7-15 year old children and adolescents, short sleep duration was associated with elevated waist circumference, and this association was observed amongst boys only [76]. In a study conducted on children and adolescents aged 6-20 years, short sleep duration was associated with lower resting energy expenditure in boys and with higher leptin levels in girls [77, 78]. These results suggest a possible gender difference in the impact of sleep duration on hormonal and physiologic parameters during childhood and adolescence [78]. Alternatively, the gender-based disparities in the association between sleep and MHO may reflect differences in lifestyle-related factors. In fact, the widespread use of videogames and technology among teenage boys, may delay the onset of sleep, possibly introducing daytime napping as well [79]. Consequently, this group is at higher risk of disruption of the normal circadian rhythmicity related to sleep and the hormonal systems involved in metabolic regulation [79]. Taken together, our findings highlight the need for the integration of sleep in the development of effective prevention, treatment, and intervention programs targeting adolescent obesity and related metabolic abnormalities [76, 80]. The inclusion of sleep questions in health assessments can provide a clear picture of whether the adolescent has good or poor sleeping habits and help in planning for lifestyle and behavior modification interventions when needed [80].

In the present study, there was no association between physical activity, sedentary behavior, and MHO amongst adolescents. The link between physical activity and MHO status in youth is not well understood, since only few studies have examined this association. Prince et al. (2014) [12] showed that higher physical activity was independently associated with $\mathrm{MHO}$ amongst Canadian children, while Camhi et al. (2013), Heinzle et al. (2015) and Senechayl et al. (2013) reported no associations between physical activity, screen time and MHO amongst US and Canadian adolescents [21, 46, 52]. The lack of association between $\mathrm{MHO}$ and physical activity in the present study may be due to the low prevalence of physical activity amongst obese adolescents in KSA whereby the frequency of engaging in physical activity for at least 30 min was less than 2 times per week in this population group. Alternatively, other factors such as cardiorespiratory or musculoskeletal fitness, which may offer additional insight as to why some obese adolescents experience metabolic abnormalities while others do not $[45,52]$, were not assessed in this study.

The strengths of this study included the large sample and the national representativeness of the study population. Anthropometric measurements were obtained using standardized protocols rather than being self-reported. The findings of this study should however be interpreted in light of the following limitations. First, the study instrument was self-administered which may be associated with recall bias, and a high cognitive burden [81]. However, the questionnaire underwent several rounds of expert review and was pilot-tested for clarity, appropriate wording and comprehension amongst the target respondent group, i.e. adolescents in KSA. Second, pubertal stage and the levels of sex hormones, which may affect the cardiometabolic profile, were not assessed in this study [22, 48, 50, 51]. In addition, direct measures of adiposity, such as fat mass, percent body fat and visceral fat, which may play a crucial role in the pathogenesis of metabolic abnormalities, were not obtained. It is also important to note that physical activity and dietary assessment were not investigated using objective measurements, but were self-reported based on questions that were formulated in congruence with those included in the Youth Risk Behavior Survey [33] and the Global School-based Student Health Survey [28, 34], with cultural adaptation. It is worth noting that, although the questionnaire inquired about the frequency of daytime sleeping, it did not allow for the assessment of nap duration or its timing during the day. In addition, the questionnaire used in the Jeeluna study did not inquire about the age of onset of obesity, and thus did not allow us to examine the association between obesity duration and MHO/MUO status in the study sample. Furthermore, 
those who consented to blood withdrawal and provided blood samples represented $58.3 \%$ of the originally surveyed population. A comparison between those who provided blood samples and those who did not, showed that socio-economic characteristics did not differ significantly between the groups. However, the group that provided blood was older $(15.9 \pm 1.83$ vs. $15.69 \pm 1.84$ years $)$, heavier (BMI: $22.77 \pm 5.92$ vs. $22.36 \pm 6.06 \mathrm{~kg} / \mathrm{m}^{2}$ ), and included more girls compared to boys (50.9\% girls vs. $49.1 \%$ boys) $(p<0.05)$. Such differences could have resulted in an underestimation of MHO in the study sample, given that BMI has been repetitively shown to be inversely associated with $\mathrm{MHO}$ in youth. Despite the above, these differences in age, BMI and gender are less likely to have affected the association between dietary, anthropometric and sleep indicators, as identified in this study. Lastly, the cross-sectional nature of this study does not allow for causality inference. There is a need for longitudinal studies to further confirm the role of adiposity, dietary, psychosocial, socio-demographic and lifestyle- related factors in modulating metabolic profiles in obese youth.

\section{Conclusion}

In a national survey conducted in KSA, this study showed that approximately one out of five adolescents had a favorable metabolic profile, despite being obese. The increasing rate of pediatric obesity underscores the importance of distinguishing $\mathrm{MHO}$ and MUO, to optimize the delivery of health services for obesity management in a manner that is both efficient and effective [50]. This study has importantly identified anthropometric factors as predictors of $\mathrm{MHO}$ and suggested gender-based differences in the association between diet, sleep and MHO in adolescents. The poor agreement between the two MHO definitions adopted in this study (IDF and CR) and the fact that the use of different definitions yielded different predictors highlight the need for harmonized definitions for the identification of $\mathrm{MHO}$ in adolescence. Taken together, the study's findings provide additional insights into the heterogeneity of obesity, while also having possible impact on intervention strategies aimed at improving metabolic heath in obese adolescents in a region that harbors one of the highest burdens of pediatric obesity worldwide.

\section{Additional file}

Additional file 1: Table S1. Psychosocial variables in the total sample of obese adolescents $(n=1047)$ and by MUO or MHO status. (DOCX $17 \mathrm{~kb})$

\section{Abbreviations}

ATPIII: Adult Treatment Panel III; BMI: Body Mass Index; BP: Blood pressure; CDC: Center for Disease Control and Prevention; Cl: Confidence interval: CIMT: Carotid intima media thickness; cm: Centimeters; CR: Cardiovascular risk; CVD: Cardiovascular diseases; d: Day; DBP: Diastolic blood pressure; EMR: Eastern Mediterranean Region; GCC: Gulf Cooperation Council; HDL-
C: High density lipoprotein-cholesterol; HOMA: Homeostasis Model Assessment; hrs: Hours; IDF: International Diabetes Federation;

IRB: Institutional review board; KAIMRC: King Abdullah International Medical Research Center; kg: Kilograms; kg/m²: Kilograms per squared meters;

KSA: Kingdom of Saudi-Arabia; LDL-C: Low density lipoprotein-cholesterol; $\mathrm{MHO}$ : Metabolically healthy obesity; $\mathrm{mm} \mathrm{Hg}$ : Millimeters of mercury; mmol/ L: Millimoles per liter; mn: Minutes; MOE: Ministry of Education;

MUO: Metabolically unhealthy obese; NCD: Non-communicable diseases; NCEP: National Cholesterol Education Program; OR: Odd ratio; SBP: Systolic blood pressure; TC: Total cholesterol; TG: Triglycerides; US: United States; WC: Waist circumference; WHO: World Health Organization

\section{Acknowledgements}

We would like to thank Dr. Waleed Tamimi from the Department of Pathology and Laboratory Medicine at King Abdulaziz Medical City for providing the technical laboratory related information.

\section{Funding}

This work was supported by King Abdullah International Medical Research Center (Protocol RC08-092).

\section{Availability of data and materials}

The datasets used and/or analyzed during the current study are available from the corresponding author on reasonable request.

\section{Authors' contribution}

LN contributed to the conceptualization of the study objectives and methodology, write up of the paper and the interpretation of the data. HT conducted data analyses and contributed to data interpretation and the write up of the manuscript. AM contributed to data analysis and data interpretation; FSA led and supervised the implementation of the Jeeluna survey in KSA, obtained funding, contributed to data interpretation, and critically reviewed the manuscript. LN and HT contributed equally to this manuscript. All authors have contributed to, read and approved the final manuscript.

\section{Ethics approval and consent to participate}

The study protocol was approved by the institutional review board (IRB) and ethics committee at King Abdullah International Medical Research Center (KAIMRC) and the Ministry of Education (MOE). Written parental consent and student assent were obtained prior to subjects' enrollment in the study. Students were assured that all the responses that they provided on the questionnaire would remain anonymous and confidential.

\section{Consent for publication}

Not applicable.

\section{Competing interests}

The authors declare that they have no competing interests.

\section{Publisher's Note}

Springer Nature remains neutral with regard to jurisdictional claims in published maps and institutional affiliations.

\section{Author details}

${ }^{1}$ Department of Nutrition and Food Science, Faculty of Agricultural and Food Sciences, American University of Beirut, P.O. Box 11-0236, Riad El Solh, Beirut, Lebanon. ${ }^{2}$ Clinical Research Institute, Biostatistics Unit, American University of Beirut Medical Center, Riad El Solh, Beirut, Lebanon. ${ }^{3}$ Department of Pediatrics and Adolescent Medicine, AlDara Hospital and Medical Center, P.O. Box 1105, Riyadh 11431, Saudi Arabia. ${ }^{4}$ Department of Population, Family, and Reproductive Health, Bloomberg School of Public Health, Johns Hopkins University, Baltimore, MD, USA.

Received: 16 November 2017 Accepted: 8 August 2018 Published online: 23 August 2018

\section{References}

1. Hossain P, Kawar B, El Nahas M. Obesity and diabetes in the developing world_-a growing challenge. N Engl J Med. 2007;356:213-5. 
2. Food and Nutrition Administration/Ministry of Health Kuwait. Kuwait National Surveillance System (KNSS). Annu Rep. 2013:2014.

3. Rootwelt MS, Christine, Beinnes Fosse K, Tuffaha A, Said H, Sandridge A, Janahi I, Greer W, Hedin L. Qatar's Youth Is Putting On Weight: The Increase In Obesity Between 2003 And 2009. In Qatar Foundation Annual Research Conference. 2014: HBSP1130.

4. Wang Y, Lobstein T. Worldwide trends in childhood overweight and obesity. Pediatr Obes. 2006;1:11-25.

5. Black RE, Victora CG, Walker SP, Bhutta ZA, Christian P, De Onis M, Ezzati M, Grantham-McGregor S, Katz J, Martorell R. Maternal and child undernutrition and overweight in low-income and middle-income countries. Lancet. 2013; 382:427-51.

6. Nasreddine L, Ouaijan K, Mansour M, Adra N, Sinno D, Hwalla N. Metabolic syndrome and insulin resistance in obese prepubertal children in Lebanon: a primary health concern. Ann Nutr Metab. 2010;57:135-42.

7. Weiss R, Dziura J, Burgert TS, Tamborlane W, Taksali SE, Yeckel CW, Allen K, Lopes M, Savoye M, Morrison J. Obesity and the metabolic syndrome in children and adolescents. N Engl J Med. 2004;350:2362-74.

8. Ebbeling CB, Pawlak DB, Ludwig DS. Childhood obesity: public-health crisis, common sense cure. Lancet. 2002;360:473-82.

9. Krebs NF, Jacobson MS. Prevention of pediatric overweight and obesity. Pediatrics. 2003;112:424-30.

10. Bonora E, Kiechl S, Willeit J, Oberhollenzer F, Egger G, Targher G, Alberiche M, Bonadonna RC, Muggeo M. Prevalence of insulin resistance in metabolic disorders: the Bruneck study. Diabetes. 1998;47:1643-9.

11. Ferrannini E, Natali A, Bell P, Cavallo-Perin P, Lalic N, Mingrone G. Insulin resistance and hypersecretion in obesity. European Group for the Study of insulin resistance (EGIR). J Clin Invest. 1997;100:1166-73.

12. Prince RL, Kuk JL, Ambler KA, Dhaliwal J, Ball GD. Predictors of metabolically healthy obesity in children. Diabetes Care. 2014;37:1462-8.

13. Hinnouho G-M, Czernichow S, Dugravot A, Batty GD, Kivimaki M, SinghManoux A. Metabolically healthy obesity and risk of mortality. Diabetes Care. 2013;36:2294-300.

14. Lassale C, Tzoulaki I, Moons KG, Sweeting M, Boer J, Johnson L, Huerta JM Agnoli C, Freisling H, Weiderpass E. Separate and combined associations of obesity and metabolic health with coronary heart disease: a pan-European case-cohort analysis. Eur Heart J. 2017;39:397-406.

15. Lee H-J, Choi E-K, Lee S-H, Kim Y-J, Han K-D, Oh S. Risk of ischemic stroke in metabolically healthy obesity: a nationwide population-based study. PLoS One. 2018;13:e0195210.

16. Zheng R, Zhou D, Zhu Y. The long-term prognosis of cardiovascular disease and all-cause mortality for metabolically healthy obesity: a systematic review and meta-analysis. J Epidemiol Community Health. 2016jech-2015-206948.

17. Bell JA, Kivimaki M, Hamer M. Metabolically healthy obesity and risk of incident type 2 diabetes: a meta-analysis of prospective cohort studies. Obes Rev. 2014;15:504-15.

18. Johnson ST, Kuk JL, Mackenzie KA, Huang TT, Rosychuk RJ, Ball GD. Metabolic risk varies according to waist circumference measurement site in overweight boys and girls. J Pediatr. 2010;156:247-52. e1.

19. Sims EA. Are there persons who are obese, but metabolically healthy? Metabolism. 2001;50:1499-504.

20. Huang TT-K, Sun SS, Daniels SR. Understanding the nature of metabolic syndrome components in children and what they can and cannot do to predict adult disease. J Pediatr. 2009;155:e13.

21. Heinzle S, Ball G, Kuk J. Variations in the prevalence and predictors of prevalent metabolically healthy obesity in adolescents. Pediatr Obes. 2016;11:425-33.

22. Bervoets L, Massa G. Classification and clinical characterization of metabolically "healthy" obese children and adolescents. J Pediatr Endocrinol Metab. 2016:29:553-60

23. Coleman K, Austin BT, Brach C, Wagner EH. Evidence on the chronic care model in the new millennium. Health Aff. 2009:28:75-85.

24. Camhi SM, Crouter SE, Hayman LL, Must A, Lichtenstein AH. Lifestyle behaviors in metabolically healthy and unhealthy overweight and obese women: a preliminary study. PLoS One. 2015;10:e0138548.

25. Hankinson AL, Daviglus ML, Horn LV, Chan Q, Brown I, Holmes E, Elliott P, Stamler J. Diet composition and activity level of at risk and metabolically healthy obese American adults. Obesity. 2013;21:637-43.

26. Matta J, Nasreddine L, Jomaa L, Hwalla N, Mehio Sibai A, Czernichow S, Itan L, Naja F. Metabolically healthy overweight and obesity is associated with higher adherence to a traditional dietary pattern: a cross-sectional study among adults in Lebanon. Nutrients. 2016;8:432.
27. Mehio Sibai A, Nasreddine L, Mokdad AH, Adra N, Tabet M, Hwalla N. Nutrition transition and cardiovascular disease risk factors in Middle East and North Africa countries: reviewing the evidence. Ann Nutr Metab. 2010; 57:193-203.

28. AlBuhairan FS, Tamim H, Al Dubayee M, AIDhukair S, Al Shehri S, Tamimi W, El Bcheraoui C, Magzoub ME, De Vries N, Al Al. Time for an adolescent health surveillance system in Saudi Arabia: findings from "Jeeluna". J Adolesc Health. 2015;57:263-9.

29. El-Hazmi MA, Warsy AS. A comparative study of prevalence of overweight and obesity in children in different provinces of Saudi Arabia. J Trop Pediatr. 2002:48:172-7.

30. International Diabetes Federation. The IDF consensus definition of the metabolic syndrome in children and adolescents. 2006. https://www.idf.org/ e-library/consensus-statements/61-idf-consensus-definition-of-metabolicsyndrome-in-children-and-adolescents. Accessed 5 Sept 2011.

31. Onis Md, Onyango AW, Borghi E, Siyam A, Nishida C, Siekmann J. Development of a WHO growth reference for school-aged children and adolescents. Bull World Health Organ. 2007;85:660-7.

32. Kuczmarski RJ, Ogden CL, Guo SS, Grummer-Strawn LM, Flegal KM, Mei Z, Wei R, Curtin LR, Roche AF, Johnson CL. CDC growth charts for the United States: methods and development. Vital Health Stat. 2000;11:20021-190.

33. Kann L, Kinchen S, Shanklin SL, Flint KH, Hawkins J, Harris WA, Lowry R, Olsen EOM, McManus T, Chyen D. Youth risk behavior surveillance-United States. 2013;2014

34. World Health Organization. Global school-based student health survey (GSHS). WHO CHP. 2009.

35. Center for Disease Control and Prevention-World Health Organization: Global School-Based Student Health Survey. Jordan GSHS Report. 2004.

36. AlBuhairan F. Jeeluna study: national assessment of the health needs of adolescents in Saudi Arabia. Riyadh: King Adbullah International Medical Research Center, ISBN: 978-603-90316-1-1.2016.

37. Malak MZ. Patterns of health-risk behaviors among Jordanian adolescent students. Health. 2015;7:58

38. Lee RD, Nieman DC. Nutritional Assessment. 4th ed. New York: McGraw-Hill; 2007

39. Marfell-Jones MJ, Stewart A, De Ridder J. International standards for anthropometric assessment. 2012.

40. Pediatrics AAo. National high blood pressure education program working group on high blood pressure in children and adolescents. Pediatrics 2004;114:iv-iv.

41. Cook S, Weitzman M, Auinger $P$, Nguyen $M$, Dietz WH. Prevalence of a metabolic syndrome phenotype in adolescents: findings from the third National Health and nutrition examination survey, 1988-1994. Arch Pediatr Adolesc Med. 2003;157:821-7.

42. Lee S, Bacha F, Gungor N, Arslanian S. Comparison of different definitions of pediatric metabolic syndrome: relation to abdominal adiposity, insulin resistance, adiponectin, and inflammatory biomarkers. J Pediatr. 2008;152:177-84. e3.

43. Fernández JR, Redden DT, Pietrobelli A, Allison DB. Waist circumference percentiles in nationally representative samples of African-American, European-American, and Mexican-American children and adolescents. J Pediatr. 2004;145:439-44.

44. Slagter SN, Corpeleijn E, Van Der Klauw MM, Sijtsma A, Swart-Busscher LG, Perenboom CW, De Vries JH, Feskens EJ, Wolffenbuttel BH, Kromhout D. Dietary patterns and physical activity in the metabolically (un) healthy obese: the Dutch lifelines cohort study. Nutr J. 2018;17:18.

45. Cadenas-Sanchez C, Ruiz JR, Labayen I, Huybrechts I, Manios Y, GonzálezGross M, Breidenassel C, Kafatos A, De Henauw S, Vanhelst J. Prevalence of metabolically healthy but overweight/obese phenotype and its association with sedentary time, physical activity, and fitness. J Adolesc Health. 2017;

46. Camhi SM, Waring ME, Sisson SB, Hayman LL, Must A. Physical activity and screen time in metabolically healthy obese phenotypes in adolescents and adults. J Obes. 2013;2013

47. Chun S, Lee S, Son H-J, Noh H-M, Oh H-Y, Jang HB, Lee H-J, Kang J-H, Song $\mathrm{H}-J$, Paek Y-J. Clinical characteristics and metabolic health status of obese Korean children and adolescents. Korean J Fam Med. 2015;36:233-8.

48. Ding W, Yan Y, Zhang M, Cheng H, Zhao X, Hou D, Mi J. Hypertension outcomes in metabolically unhealthy normal-weight and metabolically healthy obese children and adolescents. J Hum Hypertens. 2015;29:548.

49. Elmaogullari S, Demirel F, Hatipoglu N. Risk factors that affect metabolic health status in obese children. J Pediatr Endocrinol Metab. 2017;30:49-55.

50. Li L, Yin J, Cheng H, Wang Y, Gao S, Li M, Grant SF, Li C, Mi J, Li M. Identification of genetic and environmental factors predicting metabolically 
healthy obesity in children: data from the BCAMS study. J Clin Endocrinol Metab. 2016;101:1816-25.

51. Reinehr T, Wolters B, Knop C, Lass N, Holl RW. Strong effect of pubertal status on metabolic health in obese children: a longitudinal study. J Clin Endocrinol Metab. 2014;100:301-8.

52. Sénéchal M, Wicklow B, Wittmeier $\mathrm{K}$, Hay J, Maclntosh AC, Eskicioglu P, Venugopal N, McGavock JM. Cardiorespiratory fitness and adiposity in metabolically healthy overweight and obese youth. Pediatrics. 2013;132:e85-92.

53. Vukovic R, Milenkovic T, Mitrovic K, Todorovic S, Plavsic L, Vukovic A, Zdravkovic D. Preserved insulin sensitivity predicts metabolically healthy obese phenotype in children and adolescents. Eur J Pediatr. 2015;174:1649-55.

54. Camhi SM, Evans EW, Hayman LL, Lichtenstein AH, Must A. Healthy eating index and metabolically healthy obesity in US adolescents and adults. Prev Med. 2015;77:23-7.

55. Mangge H, Zelzer S, Puerstner P, Schnedl WJ, Reeves G, Postolache TT, Weghuber D. Uric acid best predicts metabolically unhealthy obesity with increased cardiovascular risk in youth and adults. Obesity. 2013;21

56. Weghuber D, Zelzer S, Stelzer I, Paulmichl K, Kammerhofer D, Schnedl W, Molnar D, Mangge H. High risk vs."metabolically healthy" phenotype in juvenile obesity-neck subcutaneous adipose tissue and serum uric acid are clinically relevant. Exp Clin Endocrinol Diabetes. 2013;121:384-90.

57. Phillips CM. Metabolically healthy obesity across the life course: epidemiology, determinants, and implications. Ann N Y Acad Sci. 2017;1391:85-100.

58. Li S, Chen W, Srinivasan SR, Xu J, Berenson GS. Relation of childhood obesity/cardiometabolic phenotypes to adult cardiometabolic profile: the Bogalusa heart study. Am J Epidemiol. 2012;176:S142-S9.

59. Eloi JC, Epifanio M, de Gonçalves MM, Pellicioli A, Vieira PFG, Dias HB, Bruscato N, Soder RB, Santana JCB, Mouzaki M. Quantification of abdominal fat in obese and healthy adolescents using 3 tesla magnetic resonance imaging and free software for image analysis. PLoS One. 2017;12:e0167625.

60. Hatipoglu N, Mazicioglu MM, Poyrazoglu S, Borlu A, Horoz D, Kurtoglu S. Waist circumference percentiles among Turkish children under the age of 6 years. Eur J Pediatr. 2013;172:59-69.

61. McCarthy HD, Ellis SM, Cole TJ. Central overweight and obesity in British youth aged 11-16 years: cross sectional surveys of waist circumference. BMJ. 2003;326:624

62. Esmaillzadeh A, Kimiagar M, Mehrabi Y, Azadbakht L, Hu FB, Willett WC. Fruit and vegetable intakes, $\mathrm{C}$-reactive protein, and the metabolic syndrome. Am J Clin Nutr. 2006;84:1489-97.

63. Collins C, Watson J, Burrows T. Measuring dietary intake in children and adolescents in the context of overweight and obesity. Int J Obes. 2010;34:1103.

64. Collins CE, Dewar DL, Schumacher TL, Finn T, Morgan PJ, Lubans DR. 12 month changes in dietary intake of adolescent girls attending schools in low-income communities following the NEAT girls cluster randomized controlled trial. Appetite. 2014;73:147-55.

65. Moore LL, Singer MR, Qureshi MM, Bradlee ML, Daniels SR. Food group intake and micronutrient adequacy in adolescent girls. Nutrients. 2012;4: 1692-708.

66. Spruyt K, Molfese DL, Gozal D. Sleep duration, sleep regularity, body weight, and metabolic homeostasis in school-aged children. Pediatrics. 2011;127: e345-e52.

67. Yamada T, Hara K, Shojima N, Yamauchi T, Kadowaki T. Daytime napping and the risk of cardiovascular disease and all-cause mortality: a prospective study and dose-response meta-analysis. Sleep. 2015;38:1945-53.

68. Yang L, Xu Z, He M, Yang H, Li X, Min X, Zhang C, Xu C, Angileri F, Légaré S. Sleep duration and midday napping with 5 -year incidence and reversion of metabolic syndrome in middle-aged and older Chinese. Sleep. 2016;39:1911-8.

69. Yang L, Yang H, He M, Pan A, Li X, Min X, Zhang C, Xu C, Zhu X, Yuan J. Longer sleep duration and midday napping are associated with a higher risk of CHD incidence in middle-aged and older Chinese: the DongfengTongji cohort study. Sleep. 2016;39:645-52.

70. Jakubowski KP, Hall MH, Marsland AL, Matthews KA. Is daytime napping associated with inflammation in adolescents? Health Psychol. 2016;35:1298

71. Landis AM, Parker KP, Dunbar SB. Sleep, hunger, satiety, food cravings, and caloric intake in adolescents. J Nurs Scholarship. 2009;41:115-23.

72. Bell JF, Zimmerman FJ. Shortened nighttime sleep duration in early life and subsequent childhood obesity. Arch Pediatr Adolesc Med. 2010;164:840-5.

73. Tikotzky L, De Marcas G, HAR-TOOV J, Dollberg S, BAR-HAIM Y, Sadeh A. Sleep and physical growth in infants during the first 6 months. J Sleep Res. 2010;19:103-10.
74. Pervanidou P, Chrousos GP. Stress and obesity/metabolic syndrome in childhood and adolescence. Pediatr Obes. 2011;6:21-8.

75. Ward TM, Gay C, Alkon A, Anders TF, Lee KA. Nocturnal sleep and daytime nap behaviors in relation to salivary cortisol levels and temperament in preschool-age children attending child care. Biol Res Nurs. 2008;9:244-53.

76. Eisenmann JC, Ekkekakis P, Holmes M. Sleep duration and overweight among Australian children and adolescents. Acta Paediatr. 2006;95:956-63.

77. Hitze B, Bosy-Westphal A, Bielfeldt F, Settler U, Plachta-Danielzik S, Pfeuffer M, Schrezenmeir J, Mönig H, Müller M. Determinants and impact of sleep duration in children and adolescents: data of the Kiel obesity prevention study. Eur J Clin Nutr. 2009;63:739.

78. Van Cauter E, Knutson KL. Sleep and the epidemic of obesity in children and adults. Eur J Endocrinol. 2008;159:S59-66.

79. Klingenberg L, Chaput J-P, Holmbäck U, Visby T, Jennum P, Nikolic M, Astrup A, Sjödin A. Acute sleep restriction reduces insulin sensitivity in adolescent boys. Sleep. 2013;36:1085-90.

80. Chaput J-P, Dutil C. Lack of sleep as a contributor to obesity in adolescents: impacts on eating and activity behaviors. Int J Behav Nutr Phys Act. 2016;13:103.

81. Bowling A. Mode of questionnaire administration can have serious effects on data quality. J Public Health. 2005;27:281-91.

82. Feinberg I. Recommended sleep durations for children and adolescents: the dearth of empirical evidence. 2013.
Ready to submit your research? Choose BMC and benefit from:
- fast, convenient online submission
- thorough peer review by experienced researchers in your field
- rapid publication on acceptance
- support for research data, including large and complex data types
- gold Open Access which fosters wider collaboration and increased citations
- maximum visibility for your research: over $100 \mathrm{M}$ website views per year
At BMC, research is always in progress.
Learn more biomedcentral.com/submissions 